\title{
Journal of Nuclear Medicine \& Radiation Therapy
}

\section{Monte Carlo Calculations of Dosimetric Parameters for a New Design ${ }^{125}$ I Source}

\author{
Mahdi Sadeghi ${ }^{* *}$, Zahra Khanmohammadi ${ }^{2}$ and Ali Jafari ${ }^{3}$ \\ ${ }^{1}$ Medical Physics Department, School of Medicine, Iran University of Medical Science, Tehran, Iran \\ ${ }^{2}$ Department of Medical Radiation Engineering, Science and Research Branch, Islamic Azad University, Tehran, Iran \\ ${ }^{3}$ Department of Physics, IRIB University, Tehran, Iran
}

"Corresponding author: Mahdi Sadeghi, Department of Medical physics, School of Medicine, Iran University of Medical Science, Tehran, Iran, E-mail: sadeghi.m@iums.ac.ir

Received date: June 30, 2018; Accepted date: July 25, 2018; Published date: July 30, 2018

Copyright: (2018 Sadeghi M, et al. This is an open-access article distributed under the terms of the Creative Commons Attribution License, which permits unrestricted use, distribution, and reproduction in any medium, provided the original author and source are credited.

\begin{abstract}
Objective: ${ }^{125} \mathrm{I}$ brachytherapy sources are being used for interstitial implants in tumor sites such as the prostate.

Methods: Monte Carlo radiation transport code version MCNP 5 was used to calculate the dosimetry parameters around the source in accordance with the update American Association of Physicists in Medicine (AAPM) Task Group No. 43 report (TG-43U1).

Results: For this source, the dose rate constant $\Lambda$, the radial dose function $g(r)$, and the anisotropy function $F(r, \theta)$, were obtained. The results indicated the dose rate constant of $0.934 \pm 0.1 \% c G y h^{-1} \mathrm{U}^{-1}$ for the IR04-125I source. Brachytherapy seeds model, $6711-{ }^{125}$, BT-125I and MED3631-A/M ${ }^{125}$ |, carrying ${ }^{125}$ I radio nuclides, was modelled and benchmarked against previously published values.

Conclusion: Finally the calculated results were compared with published results for those of other source manufacturers. The Monte Carlo calculated results with other published shows that the calculated values are in acceptable range.
\end{abstract}

Keywords: Dosimetry; Brachytherapy; TG-43U1; MCNP5; ${ }^{125} \mathrm{I}$

\section{Introduction}

Encapsulated radioactive materials are used in several medical applications. Common tumor sites treated with such materials are prostate, breast, eye, and cervix [1], Use of ultrasound-guided brachytherapy seed implantation for prostate cancer has increased greatly since the technique was developed in the early 1980s. The reasons for the increase are many, including patient convenience (one treatment versus many for external-beam radiotherapy), reduced side effects as compared with radical prostatectomy, and greater cost effectiveness [2,3]. For treatment of prostate cancer, ${ }^{125} \mathrm{I}$ is used because of its low energy emissions, which allow for a rapid decrease in dose with distance [4]. With increasing demand for ${ }^{125}$ I seed sources, new source has been designed. Due to the low energy of the emitted radiation, obtaining the dosimetric data necessary for clinical implementation can be challenging. The American Association of Physicists in Medicine (AAPM) Radiation Therapy committee recommends that each new brachytherapy source have a thorough and redundant dosimetric characterization before it is clinically used [5].

Monte Carlo simulation was used to determine the TG- 43U1 source parameters of the source design in this study. In this work, we used MCNP 5 for calculating the anisotropy function, $F(r, \theta)$, the radial dose function, gl (r) the dose rate constant, $\Lambda$ [6-8]. Finally, a comparison of the derived ${ }^{125}$ I source dosimetry data with data for other ${ }^{125}$ I seeds is presented.

\section{Materials and Methods}

\section{${ }^{125}$ I source description}

The schematic diagram of IR04- ${ }^{125} \mathrm{I}$ source is shown in Figure 1 with $4.8 \mathrm{~mm}$ length by $0.8 \mathrm{~mm}$ diameter capsule of $0.05 \mathrm{~mm}$ thick titanium $\left(\rho=4.54 \mathrm{~g} / \mathrm{cm}^{3}\right)$ that contains a palladium core having a 3.5 $\mathrm{mm}$ active length, with $0.6 \mathrm{~mm}$ thick end. The materials were chosen simply. The palladium rod of the seed was assumed to be pure palladium and the ${ }^{125} \mathrm{I}$ is in a Sodium Iodide (NaI) coating on the palladium rod, so the Monte-Carlo source was distributed uniformly throughout the outer $2 \mu \mathrm{m}$ of the palladium rod. Source activity is in the range of $0.5-3.0 \mathrm{mCi}$.

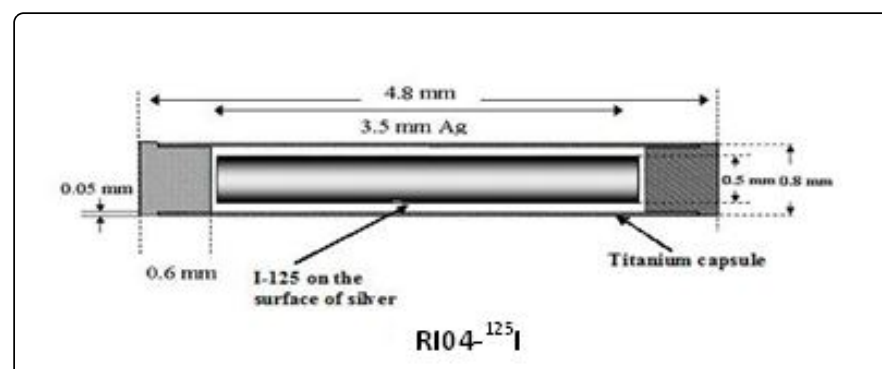

Figure 1: The geometric models of the designed IR04- ${ }^{125}$ I source used in the Monte Carlo simulations. 


\section{Monte Carlo evaluation}

Dose distributions in this work was simulated with the MCNP5 Monte Carlo (MC) radiation transport code published by Los Alamos National Laboratory and the MCPLIB04 photon cross-section library is based on the ENDF/B-VI data [9].

Particle energy flounce and cell-heating tallies ( ${ }^{*} \mathrm{~F} 4$ and F6, respectively) were employed to calculate Kerma per starting particle, which is equivalent to absorbed dose for the photon energies studied.

The ${ }^{*} \mathrm{~F} 4$ track-length estimator tally results (energy flounce) in $\mathrm{MeV}$ $\mathrm{cm}^{-2}$ were modified by Hubbell and Seltzer's tabulated $\mu \mathrm{en} \rho^{-1}\left(\mathrm{~cm}^{2} \mathrm{~g}\right.$ ${ }^{-1}$ ) values to provide MC results in dose per starting particle [10].

The F6 cell heating tally results in $\mathrm{MeV} \mathrm{g}^{-1}$ were converted to absorbed dose using constants. The source has been simulated in the center of a spherical phantom of water with $15 \mathrm{~cm}$ radius, large enough to consider all the scattering effects of the surrounding medium with an array of $1 \mathrm{~mm}$ thick detector rings.

The rings were bounded with two cones $\left(10^{\circ}\right)$ bisecting the sphere corresponding to points in two-dimensional TG-43U1 dose formalism $[11,12]$.

MC geometry for air Kerma calculations utilized a $200 \mathrm{~cm}$-radius phantom with $1 \mathrm{~mm}$-thick spherical shells spaced every $5 \mathrm{~cm}$ between 5 and $150 \mathrm{~cm}$.

The sampling volume within the spherical shells was delineated by the intersection of the spherical shells with $a \pm 8^{\circ}$ cone in the seed transverse plane.

For simulations with the $\mathrm{Al}$ filter to block Ti K-edge X-rays, a $0.08636 \mathrm{~mm}$-thick spherical Al shell $\left(\rho=2.7 \mathrm{~g} / \mathrm{cm}^{3}\right)$ was placed at $\mathrm{r}=2$ $\mathrm{cm}$ [12-19]. The MCNP F6 tally was used for calculate the dose distribution around the seeds.

For each source the geometry function was calculated for line source using the MCNP F4 tally, particle fluence $\left(1 / \mathrm{cm}^{2}\right)$, with the mass densities of all materials within the entire computational geometry set equal to zero so there were no interaction and particles streamed through the seed and phantom geometry [20-27].

The simulations were performed up to $1 \times 109$ histories in water with statistical uncertainties of $0.05 \%$ to $0.1 \%$ at 1 and $5 \mathrm{~cm}$ on the transverse plane and $2.5 \%$ and $3.5 \%$ at 1 and $5 \mathrm{~cm}$ along the long axis. In air with $7 \times 107$ histories, statistical uncertainty was $1 \%$.

\section{Results}

The comparison of MCNP-calculated value of $\Lambda$, with the previously published data for the $6711^{-125} \mathrm{I}[12,19], \mathrm{BT}^{-125} \mathrm{I}[20,21], \mathrm{IRA}^{-125} \mathrm{I}[22]$ and MED3631-A/M ${ }^{125} \mathrm{I}$ [13] brachytherapy sources demonstrate the accuracy of our simulation method (Table 1).

The Monte Carlo calculated dose rate constant of the IR04-125I source in water was found to be $0.935 \mathrm{cGy} \mathrm{h}^{-1} \mathrm{U}^{-1}$ using the MCNP 5.

According to Table 1 the dose rate constant value of the new ${ }^{125} \mathrm{I}$ source is in range with the dose rate constant values of other sources.

The Monte Carlo simulated line and point-radial dose function of the IR04- ${ }^{125}$ I source has been determined in water, over the range of 0.15 to $7 \mathrm{~cm}$.

The results are shown in Table 2. Figure 2 shows a comparison of the radial dose function of the seed with the $3500-{ }^{125} \mathrm{I},{ }^{125} 01-{ }^{125} \mathrm{I}, 6711^{-125} \mathrm{I}$ and BT- ${ }^{125} \mathrm{I}-2$ sources.

\begin{tabular}{|c|c|c|c|}
\hline Source type & Method & Medium & $\Lambda\left(\mathbf{c G y ~ h}^{-1} \mathbf{U}^{-1}\right)$ \\
\hline |R04-125| & Monte Carlo simulation ${ }^{*}$ & Liquid water & $0.935 \pm 0.01$ \\
\hline \multirow{4}{*}{ BT-125I-1 } & Monte Carlo simulation [20] & Liquid water & $0.955 \pm 0.005$ \\
\hline & TLD measurements [20] & Plastic Water ${ }^{\mathrm{TM}}$ & $0.95 \pm 0.007$ \\
\hline & Monte Carlo simulation [21] & Liquid water & $0.95 \pm 3$ \\
\hline & Monte Carlo simulation ${ }^{*}$ & Liquid water & $0.928 \pm 0.01$ \\
\hline \multirow{3}{*}{$6711-^{125}$} & Monte Carlo simulation [11] & Liquid water & $0.924 \pm 2.6$ \\
\hline & Monte Carlo simulation [19] & Liquid water & $0.942 \pm 1.76$ \\
\hline & Monte Carlo simulation ${ }^{*}$ & Liquid water & $0.921 \pm 0.01$ \\
\hline \multirow{2}{*}{$\mid$ IRA-125 } & Monte Carlo simulation [16] & Liquid water & $0.920 \pm 0.01$ \\
\hline & Monte Carlo simulation ${ }^{*}$ & Liquid water & $0.920 \pm 0.01$ \\
\hline \multirow{2}{*}{ MED3631-A/M ${ }^{125}$} & Monte Carlo simulation [5] & Liquid water & 1.067 \\
\hline & Monte Carlo simulation ${ }^{*}$ & Liquid water & $1.06 \pm 0.05$ \\
\hline
\end{tabular}

Table 1: Monte Carlo calculated dose rate constant, $\Lambda$, of IR04- ${ }^{125}$ I, BT- ${ }^{125}$ I, $6711^{-125}$ I, IRA- ${ }^{125}$ I and MED3631-A/M ${ }^{125}$ I, brachytherapy source compared with the measured and calculated values of previously published data. 
Citation: Sadeghi M, Mohammadi ZK, Jafari A (2018) Monte Carlo Calculations of Dosimetric Parameters for a New Design ${ }^{125}$ | Source. J Nucl Med Radiat Ther 9: 369. doi:10.4172/2155-9619.1000369

Page 3 of 5

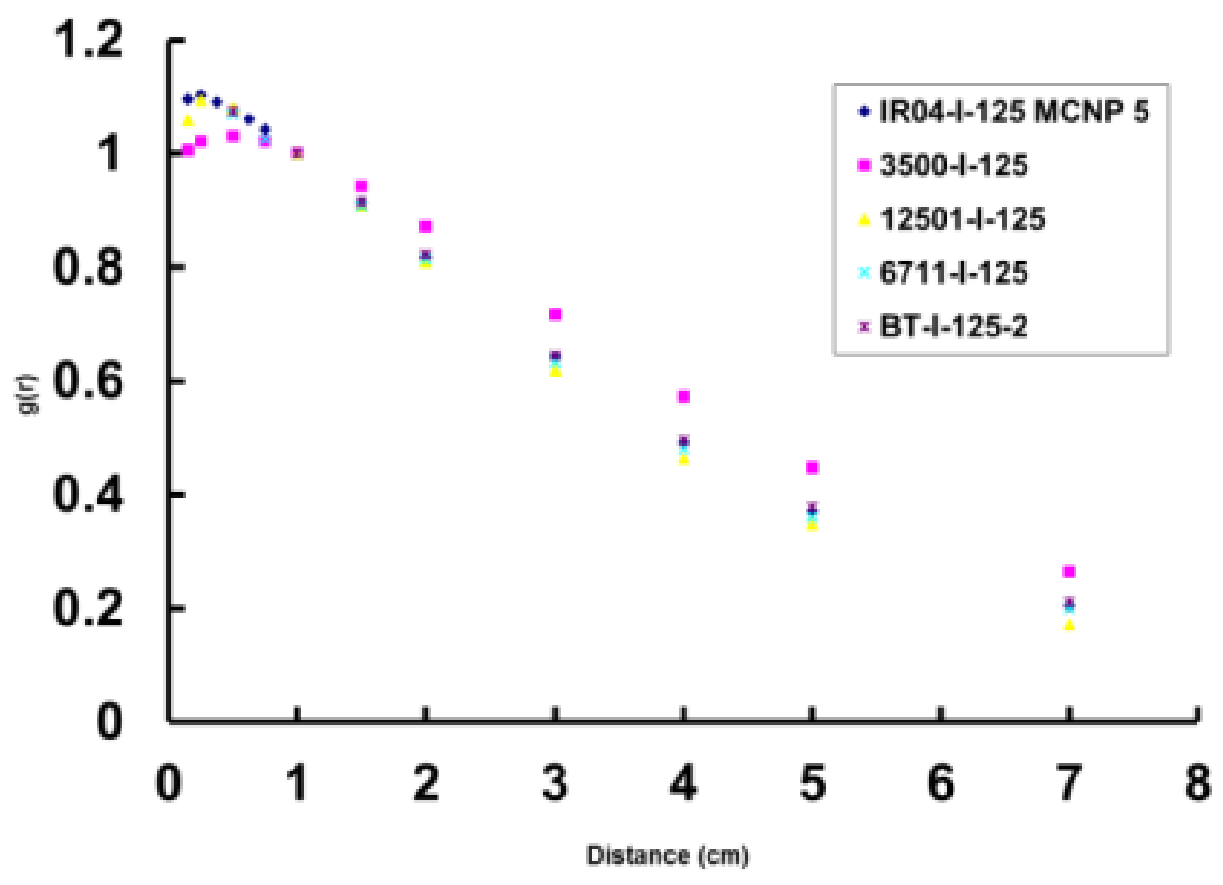

Figure 2: Comparison of the radial dose function of the seed with the $3500-{ }^{125} \mathrm{I}, 12501{ }^{125} \mathrm{I}, 6711-{ }^{125} \mathrm{I}$ and BT- $-{ }^{125} \mathrm{I}-2$ sources.

\begin{tabular}{|c|c|c|c|c|c|c|}
\hline \multirow[b]{3}{*}{ Distance, $r(\mathrm{~cm})$} & \multicolumn{5}{|c|}{$\mathrm{gL}(r)$ in water } & \multirow{2}{*}{$\begin{array}{l}\text { gP (r) in water } \\
\text { IR04-125I }\end{array}$} \\
\hline & IR04-125] & $3500-125$ & $12501-125$ & 6711 & BT- $125 \mathrm{I}-2$ & \\
\hline & MCNP5 $^{*}$ & MCNP [25] & PTRAN [26] & MCNP5 [21] & MCNP4C [21] & MCNP5 $^{*}$ \\
\hline 0.15 & 1.096 & 1.006 & 1.058 & - & - & 1.082 \\
\hline 0.25 & 1.102 & 1.021 & 1.093 & - & - & 1.087 \\
\hline 0.375 & 1.09 & - & - & - & - & 1.072 \\
\hline 0.5 & 1.075 & 1.03 & 1.08 & 1.07 & 1.074 & 1.013 \\
\hline 0.625 & 1.061 & - & - & - & - & 1.026 \\
\hline 0.75 & 1.042 & 1.021 & - & 1.025 & - & 1.029 \\
\hline 1 & 1 & 1 & 1 & 1 & 1 & 1 \\
\hline 1.5 & 0.914 & 0.943 & 0.907 & 0.908 & 0.914 & 0.917 \\
\hline 2 & 0.819 & 0.872 & 0.808 & 0.814 & 0.822 & 0.824 \\
\hline 3 & 0.643 & 0.717 & 0.618 & 0.633 & 0.645 & 0.645 \\
\hline 4 & 0.492 & 0.573 & 0.463 & 0.482 & 0.496 & 0.492 \\
\hline 5 & 0.37 & 0.448 & 0.348 & 0.361 & 0.379 & 0.37 \\
\hline 7 & 0.205 & 0.265 & 0.172 & 0.199 & 0.212 & 0.205 \\
\hline
\end{tabular}

Table 2: Monte Carlo calculations for radial dose function, gL (r) and gP (r) for line and point source geometry for IR04- ${ }^{125}$ I seed in comparison with other available sources in water. 


\section{Discussion}

These results indicate an acceptable agreement between the new ${ }^{125} \mathrm{I}$ source and other commercial available sources in distances. Many treatment planning systems require a polynomial fit to $g(r)$. For use of this data in those various treatment planning systems, the calculated $\mathrm{g}$ (r) in water in the range of $0.15 \mathrm{~cm}$ to $7 \mathrm{~cm}$ was fitted to a fifth-order polynomial function defined as follows: The anisotropy function, $\mathrm{F}$ $(\mathrm{r}, \theta)$, in this study was calculated for the IR04 ${ }^{125} \mathrm{I}$ source using
MCNP5 in a spherical water phantom at distances of $0.5,0.75,1,1.5,2$, $3,4,5$, and $7 \mathrm{~cm}$ from the source centre for angles ranging from $0^{\circ}$ to $90^{\circ}$ at $10^{\circ}$ intervals. Those values were obtained by simulating the dose rate at each angle and normalizing to the dose rate at 90 degrees and at the radial distance in question.

A complete set of anisotropy data determined by Monte Carlo calculations are tabulated in Table 3.

\begin{tabular}{|c|c|c|c|c|c|c|c|c|c|}
\hline \multirow[b]{2}{*}{ Polar angle } & \multicolumn{9}{|c|}{ Calculated $F(r, \theta)$ of IR04-125I } \\
\hline & $\mathrm{r}=0.5 \mathrm{~cm}$ & $r=0.75 \mathrm{~cm}$ & $\mathrm{r}=1 \mathrm{~cm}$ & $\mathrm{r}=1.5 \mathrm{~cm}$ & $\mathrm{r}=2 \mathrm{~cm}$ & $r=3 \mathrm{~cm}$ & $r=4 \mathrm{~cm}$ & $\mathrm{r}=5 \mathrm{~cm}$ & $\mathrm{r}=7 \mathrm{~cm}$ \\
\hline 0 & 0.166 & 0.215 & 0.249 & 0.325 & 0.362 & 0.43 & 0.485 & 0.516 & 0.537 \\
\hline 10 & 0.333 & 0.403 & 0.449 & 0.508 & 0.548 & 0.596 & 0.627 & 0.65 & 0.681 \\
\hline 20 & 0.626 & 0.657 & 0.676 & 0.709 & 0.728 & 0.732 & 0.769 & 0.778 & 0.791 \\
\hline 30 & 0.795 & 0.802 & 0.812 & 0.823 & 0.836 & 0.844 & 0.855 & 0.861 & 0.867 \\
\hline 40 & 0.897 & 0.893 & 0.896 & 0.902 & 0.906 & 0.912 & 0.922 & 0.916 & 0.918 \\
\hline 50 & 0.595 & 0.953 & 0.953 & 0.953 & 0.954 & 0.954 & 0.954 & 0.955 & 0.955 \\
\hline 60 & 1.009 & 0.995 & 0.991 & 0.988 & 0.986 & 0.972 & 0.979 & 0.978 & 0.98 \\
\hline 70 & 0.986 & 1.028 & 1.022 & 1.015 & 1.012 & 0.982 & 1.003 & 0.998 & 0.998 \\
\hline 80 & 0.996 & 0.996 & 1.004 & 1.029 & 1.028 & 1.023 & 1.017 & 1.015 & 1.013 \\
\hline 90 & 1 & 1 & 1 & 1 & 1 & 1 & 1 & 1 & 1 \\
\hline
\end{tabular}

Table 3: Monte Carlo calculated anisotropy function, $F(r, \theta)$, of designed ${ }^{125}$ I source in water

The anisotropy function, $F(r, \theta)$, describes the variation of dose in the longitudinal plane of the source. Variations are due to the distribution of radioactivity within the source, self-absorption, and oblique filtration of the radiation in the capsule material [11]. Per TG-43, the anisotropy function is defined as:

$$
F(r, \theta)=\frac{\dot{D}(r, \theta)}{\dot{D}\left(r, \theta_{0}\right)} \frac{G_{L}\left(r, \theta_{0}\right)}{G_{L}(r, \theta)}
$$

Since the proportion of primary-to-scatter dose decreases as distance increases, it is not surprising that the magnitude of the $10^{\circ}$ dip decreases as $r$ increases The larger values of $F(r, \theta)$, at the angles $<40$ for the model, $3500-{ }^{125}$ I and 125 . S06 ${ }^{125}$ I were attributed to its thinner end caps and also the pattern of the distribution of radioactive material within this source.

\section{Conclusion}

The new brachytherapy source, IR04- ${ }^{125}$ I model, was simulated in water phantom using MCNP5. Dosimetric parameters including dose rate constant, $\Lambda$, radial dose function, $\mathrm{g}(\mathrm{r})$, and anisotropy function, $\mathrm{F}$ $(r, \theta)$ of the seed were calculated according to the AAPM TG-43U1 recommendations. The results compared with other commercial sources. The information is presented in tabulated and graphical format. Based on the calculations, the dose rate constant for the IR04- ${ }^{125} \mathrm{I}$ source estimated to be $0.934 \pm 0.1 \%$ cGy h-1 $\mathrm{U}^{-1}$. Comparison of the Monte Carlo calculated results with other published shows that the calculated values are in acceptable range. So it shows that this new brachytherapy source has an acceptable dose distribution.

\section{References}

1. CA Perez, PW Grigsby, JF Williamson (1997) Clinical applications of brachytherapy. Low dose-rate. Principles and Practice of Radiation Oncology (3rdedn): 487-559.

2. Wallner K, Merrick G, True L, Cavanaugh W, Simpson C, et al. (2002) $125 \mathrm{I}$ versus $103 \mathrm{Pd}$ for low-risk prostate cancer: modality outcomes from a prospective randomized multicenter trial. Int J Radiat Oncol Biol Phys 57: 1297-303

3. Blasko JC, Wallner K, Grimm PD, Ragde H (1995) Prostate specific antigen based control following ultrasound guided $125 \mathrm{I}$ implantation for stage T1/T2 prostate carcinoma. J Urol 154: 1096-1099.

4. J. F. Williamson, "Physics of brachytherapy," in Ref. 2, pp. 405-467.

5. Rivard, Coursey, DeWerd BM, Hanson L, Huq WF, et al. (2004) Update of AAPM Task Group No. 43 Report: A revised AAPM protocol for brachytherapy dose calculations. Med Phys 31: 633-674

6. Hosseini SH, Sadeghi M, Ataeinia V (2009) Dosimetric comparison of four new design 103Pd brachytherapy sources: optimal design using silver and copper rod cores. Med Phys 36: 3080-3085.

7. Sadeghi M, Enferadi M, Shirazi A (2010) External and internal radiation therapy: Past and future direction. J Can Res Ther 6: 239-248

8. Carlo M(2008) MCNP-A General Monte Carlo N-Particle Transport Code-Version 5, Los Alamos National Laboratory

9. Hubbell JH, Seltzer SM (2004) Tables of X-Ray Mass Attenuation Coefficients and Mass Energy-Absorption Coefficients. National Institute of Standards and Technology. 
Citation: Sadeghi M, Mohammadi ZK, Jafari A (2018) Monte Carlo Calculations of Dosimetric Parameters for a New Design ${ }^{125}$ | Source. J Nucl Med Radiat Ther 9: 369. doi:10.4172/2155-9619.1000369

Page 5 of 5

10. Nath R, Anderson L, Luxton G, Weaver KA, Williamson JF (1995) Dosimetry of interstitial brachytherapy sources: recommendations of the AAPM Radiation Therapy Committee Task Group No.43. American Association of Physicists in Medicine. Med Phys 22: 209-234.

11. Melhus CS, Rivard MJ (2008) COMS eye plaque brachytherapy dosimetry simulations for 103Pd, 125I, and 131Cs. Med Phys 35: 3364-3371.

12. Anjomrouz M, Sadeghi M, Haddadi A (2013) Monte Carlo characterization of $169 \mathrm{Yb}$ as a high-dose-rate source for brachytherapy application by FLUKA code. J Appl Clin Med Phys 14: 196-205.

13. Hadadi A, Sadeghi M, Sardari D, Khanchi A, Shirazi A (2013) Monte Carlo characterization of biocompatible beta-emitting $90 \mathrm{Y}$ glass seed incorporated with the radionuclide $153 \mathrm{Sm}$ as a SPECT marker for brachytherapy applications. Journal of Applied Clinical Medical Physics 14: 90-103.

14. Hosseini H, Sadeghi M, Ataeinia V (2009) Dosimetric comparison of four new design 103Pd brachytherapy sources: optimal design using silver and copper rod cores. Med Phys. 36: 3080-3085.

15. Saidi P, Sadeghi M, Shirazi A, Tenreiro C (2011) Dosimetric parameters of the new design 103Pd brachytherapy source based on Monte Carlo study. Physica Medica 28: 13-18.

16. Saidi P, Sadeghi M, Shirazi A, Tenreiro C (2010) Monte Carlo calculation of dosimetry parameters for the IR08-103Pd brachytherapy source. Med phys 37: 2509-2509

17. Sadeghi M, Hosseini SH, Raisali G (2008) Experimental measurements and Monte Carlo calculations of dosimetric parameters of the IRA1-103Pd brachytherapy source. Appl Radiat Isot 66: 1431-1437

18. Rivard MJ (2001) Monte Carlo calculation of AAPM Task Group Report No.43 dosimetry parameters for the MED3631-A/M 125I source. Med Phys 28: 629-637.
19. Dolan J, Li Z, Williamson JF (2006) Monte Carlo and experimental dosimetry of an 125I brachytherapy seed. Med Phys 33: 4675-4684.

20. Solberg TD, DeMarco JJ, Hugo G, Wallace RE (2002) Dosimetric parameters of three new solid core I-125 brachytherapy sources. Med Phys 3: 119-134.

21. Popescu CC, Wise J, Sowards K, Meigooni AS, Ibbott GS (2000) Dosimetric characteristics of the Pharma Seed model BT-125-I source. Med Phys 27: 2174-2181.

22. Sadeghi M, Khanmohammadi Z (2011) Dosimetric characteristic of a new 125I brachytherapy source. Radiat Prot Dosimetry 147: 451-456.

23. Wallace RE (2002) Model 3500 125I brachytherapy source dosimetric characterization. Appl Radiat Isot 56: 581-587.

24. Rivard MJ (2002) Comprehensive Monte Carlo calculations of AAPM Task Group Report No. 43 dosimetry parameters for the Model 3500 IPlant 125I brachytherapy source. Appl Radiat Isot 57: 381-389.

25. Gearheat DM, Drogin A, Sowards K, Meigooni AS, Ibbott GS (2000) Dosimetric characteristics of a new 125I brachytherapy source. Med Phys 27: 2278-2285.

26. Lwata K, Yue NJ, Nath R (2004) Near-field dosimetry of 125I sources for interstitial brachytherapy implants measured using thermoluminescent sheets. Med Phys 31: 3406-3416.

27. Hedtjanrn H, Carlsson GA, Williamson Jf (2000) Monte Carlo-aided dosimetry of the symmetra model I25.S06 125I, interstitial brachytherapy seed. Med Phys 27: 1076-1085. 